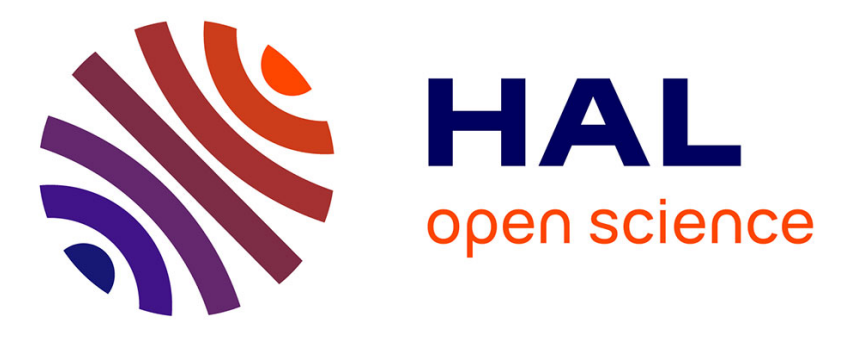

\title{
Relationship between Iberian ibex () sperm quality and level of parasitism
}

\author{
Julian Santiago-Moreno, Monica Luzón, Miguel Angel Coloma, Antonio \\ Pulido-Pastor, Félix Gómez-Guillamón, Ricardo Salas Vega, Adolfo \\ Toledano-Díaz, Antonio López-Sebastián
}

\section{To cite this version:}

Julian Santiago-Moreno, Monica Luzón, Miguel Angel Coloma, Antonio Pulido-Pastor, Félix GómezGuillamón, et al.. Relationship between Iberian ibex () sperm quality and level of parasitism. European Journal of Wildlife Research, 2010, 56 (4), pp.605-611. 10.1007/s10344-009-0356-2 . hal00551934

\section{HAL Id: hal-00551934 \\ https://hal.science/hal-00551934}

Submitted on 5 Jan 2011

HAL is a multi-disciplinary open access archive for the deposit and dissemination of scientific research documents, whether they are published or not. The documents may come from teaching and research institutions in France or abroad, or from public or private research centers.
L'archive ouverte pluridisciplinaire HAL, est destinée au dépôt et à la diffusion de documents scientifiques de niveau recherche, publiés ou non, émanant des établissements d'enseignement et de recherche français ou étrangers, des laboratoires publics ou privés. 


\title{
Relationship between Iberian ibex (Capra pyrenaica) sperm quality and level of parasitism
}

\author{
Julian Santiago-Moreno • Monica Luzón • Miguel Angel Coloma • \\ Antonio Pulido-Pastor • Félix Gómez-Guillamón • Ricardo Salas de la Vega • \\ Adolfo Toledano-Díaz • Antonio López-Sebastián
}

Received: 30 December 2008/Revised: 7 November 2009/Accepted: 4 December 2009/Published online: 5 January 2010

(C) Springer-Verlag 2009

\begin{abstract}
This paper examines the relationship between parasite infection rates and reproductive function in wild Iberian ibexes. The animals examined were 43 adult males shot during the rutting season. Gastrointestinal and pulmonary nematodes, intestinal cestodes and intestinal coccidia were determined by coprological analysis. Protozoa in the muscles were detected by biopsy. Epididymal spermatozoa were collected from recovered testes. Sperm motility, the integrity of the plasma membrane, sperm viability, sperm morphology and acrosome integrity were all evaluated. Bronchopulmonary nematode larvae were detected with a prevalence of $100 \%$ (mean intensity $216.8 \pm 65.8$; index of dispersion 476.1, indicating an aggregated pattern). A negative correlation $(R=-0.39 ; P<0.05)$ was found between the shedding of larval lungworms and the percentage of sperm morphological abnormalities. Although directional relationships could not be identified, the present findings suggest that reproductive effort imposes a cost in terms of depressed parasite resistance.
\end{abstract}

Communicated by C. Gortázar

J. Santiago-Moreno $(\bowtie) \cdot$ M. A. Coloma • A. Toledano-Díaz

A. López-Sebastián

Dpto. Reproducción Animal, INIA,

Avda. Puerta de Hierro km 5.9,

28040 Madrid, Spain

e-mail: moreno@inia.es

M. Luzón

Dpto. Sanidad Animal, Facultad de Veterinaria,

Universidad Complutense de Madrid,

Avda. Puerta de Hierro s/n,

28040 Madrid, Spain

A. Pulido-Pastor · F. Gómez-Guillamón · R. S. de la Vega Consejería de Medio Ambiente, Junta de Andalucía, D.P. Málaga, 29006 Málaga, Spain
Keywords Spanish ibex · Epididymal spermatozoa · Testes · Parasitism $\cdot$ Coprological analysis $\cdot$ Immunocompetence handicap hypothesis $\cdot$ Evolutionary trade-off

\section{Introduction}

Animals often face trade-offs between investment in antiparasite defences and activities related to self-maintenance, survival and reproduction (Zuk and Stoehr 2002; Møller and Saino 2004). The trade-off between investment in immunity and reproductive potential in males (as measured by their investment in primary and secondary sexual characteristics) has been the focus of major debate. Early studies showed a highly significant positive association between parasite infection and larger secondary sexual traits. Parasitemediated sexual selection therefore predicts that males with larger secondary sexual characteristics show greater resistance to the onset of clinical parasitic disease (Hamilton and Zuk 1982).

Parasites can impose costs on sperm production (Folstad and Skarstein 1997; Al-Qarawi et al. 2004) and reduce ejaculate quality (Sekoni 1992; Masvaer et al. 2004). Although the mechanism by which parasites directly affect reproductive performance is unclear, it is thought that they influence the nutritional status (Morris and Meek 1980) or induce hyperthermia (Rhodes 1975; Sekoni et al. 2004). Sperm quality might also be affected by immunological disorders induced by parasite infection (Liljedal et al. 1999; Masvaer et al. 2004). Since the immune system perceives sperm cells as non-self, and thus sperm cells come under attack from the immune system inside the testes (Skau and Folstad 2005), a parasitic infection that triggers immune reactions could affect spermatogenesis, ejaculate quality and fertilisation capacity (Folstad and Skarstein 1997; 
Hosken and O'Shea 2001). Alternatively, spermatogenesis might be affected by the stress (Tumkiratiwong et al. 2006) or reduced androgen levels (Isserhoff et al. 1986) induced by parasitic infection.

Recent studies suggest, however, that the intensity of parasitism increases with reproductive effort in fish (Skarstein et al. 2001), lizards (Sorci et al. 1996) and birds (Norris et al. 1994; Merila and Andersson 1999). When a host's ability to resist infection is weakened by its reproductive effort, infecting parasites might increase their reproductive output (Pelletier et al. 2005). The interaction 'sex $\times$ age' has a significant effect on larval counts of the nematode Elaphostrongylus cervi in red deer (Cervus elaphus). Adult stags have the highest counts and show the poorest immune function immediately after the rut (Vicente et al. 2007). The immunocompetence handicap hypothesis proposes that testosterone has a dual effect, enhancing the sexual characteristics of males but depressing their immune response (Folstad and Karter 1992). Indeed, it has been shown that testosterone imposes a cost in terms of depressed parasite resistance in natural populations of red deer (Malo et al. 2009). Testosterone has also been shown to increase susceptibility to helminth infections in many species, and it is now broadly accepted that males are more susceptible to parasitic infections than females (Alexander and Stimson 1988).

Selection for investment in reproduction at the expense of parasite resistance is usually more pronounced in males than in females, particularly so in species in which male reproductive competition is extreme but little male energy is invested in offspring care (Zuk 1990; Zuk and Stoehr 2002). The Iberian ibex (Capra pyrenaica) is a wild caprine found only in the Iberian Peninsula (Acevedo and Cassinello 2009). Like other highly polygynous ungulates, ibex males are subjected to intense intra-sexual competition during the rut. Given the immunosuppressive effects of testosterone, they ought to experience a certain immunodepression and suffer more from parasitic infections; the aim of this work was to determine whether this hypothesis holds by examining the relationship between reproductive function and parasite infection rates in Iberian ibexes.

\section{Materials and methods}

The animals examined in this study were 43 adult males (9-14 years of age) legally killed by hunters during the rutting season (November/December 2007) in the Tejeda $y$ Almijara (UTM coordinates 30S 400,785-420,937 4,084,512-4,066,334) and Serranía de Ronda (30S $331,399-329,9434,049,749-4,061,586)$ game reserves in southern Spain $\left(36^{\circ} \mathrm{N}\right.$ latitude). At present, the number of animals in these game reserves, estimated by distance sampling (Buckland et al. 2001), is $<6$ animals $100 \mathrm{ha}^{-1}$. The age of the animals was determined from the growth marks on their horns (Fandos 1995). All animals were selectively hunted for their relatively small horn development, and showed homogeneous horn morphometry (mean base perimeter of the horn $=19.23 \pm 0.19 \mathrm{~cm}$ [range $18-20 \mathrm{~cm}$ ]; mean length of the horn $=53.13 \pm 0.77 \mathrm{~cm}$ [range $47-59 \mathrm{~cm}]$ ).

Testes with the scrotal sac were transported to the laboratory immediately after removal. All samples were maintained at ambient temperature (about $12^{\circ} \mathrm{C}$ ) during transport to the laboratory and during processing. After removing the testes from the scrotal sac, the diameter (length) of each was measured with a tape. Testicle size was used as an index of endocrine function. Recent studies in Iberian ibex, European mouflon (Ovis orientalis musimon; Toledano-Díaz et al. 2007) and red deer (Malo et al. 2009) have emphasised the strong relationship between plasma testosterone concentrations and testis size. This variable has been successfully used as a means of indirectly evaluating testicular endocrine function in earlier work performed at our laboratory (Santiago-Moreno et al. 2000, 2005).

The cauda epididymides were isolated and epididymal spermatozoa were collected from the surrounding connective tissue according to a previously described technique (Santiago-Moreno et al. 2004) within 8 h of death. Total sperm concentrations were calculated using a Neubauer chamber (Marienfeld, Lauda-Königshofen, Germany) after the sperm mass was diluted by adding $1.0 \mathrm{ml}$ of a medium composed of $3.8 \%$ tris $\left(\mathrm{w} \mathrm{v} \mathrm{v}^{-1}\right), 2.2 \%$ citric acid $\left(\mathrm{w} \mathrm{v}^{-1}\right)$, $0.6 \%$ glucose $\left(\mathrm{w} \mathrm{v}^{-1}\right)$ and $6 \%$ egg yolk $\left(\mathrm{v} \mathrm{v}^{-1}\right)$. Sperm motility, structural morphology and acrosome and plasma membrane integrity were assessed to determine the in vitro sperm quality of each sample. The percentage of motile spermatozoa and the quality of motility were evaluated subjectively in pre-warmed samples $\left(37^{\circ} \mathrm{C}\right.$; placed on a warming plate) using a phase-contrast microscope (Zeiss, Germany) at $400 \times$. The vigour of sperm movement was scored on a scale from 0 (lowest) to 5 (highest). Sperm viability was assessed by staining an aliquot of sperm suspension with nigrosin-eosin (Campbell et al. 1956). Simultaneously, plasma membrane integrity was assessed using the hypo-osmotic swelling test (Jeyendran et al. 1984). Morphological examinations of 200 glutaraldehydefixed sperm cells were made by phase-contrast microscopy, categorising the different cell components as either normal or with abnormalities. Epididymal spermatozoa with cytoplasmic droplets were considered morphologically normal since this reflects a normal stage of sperm maturation. The percentage of spermatozoa with intact acrosomes was assessed by observing samples fixed in buffered $2 \%$ glutaraldehyde solution at $37^{\circ} \mathrm{C}$ and examining 200 spermatozoa by phase-contrast microscopy at $1,000 \times$ (Pursel and Johnson 1974). 
Table 1 Intensity (mean \pm S.E.) of parasitism, prevalence of parasitism and index of dispersion in the 43 Iberian ibex males studied

GIN gastrointestinal nematodes; $B P N$ bronchopulmonary nematodes (Protostrongylidae)

\begin{tabular}{lccc}
\hline & Intensity [min-max] & Prevalence (\%) & Index of dispersion \\
\hline GIN (Strongylida), epg & $219.4 \pm 37.7[50-600]$ & 85.7 & 148.7 \\
Cestodes (Moniezia) (epg) & $175.0 \pm 75.0[100-250]$ & 9.5 & 200.6 \\
Coccidiae (Eimeria), (opg) & $218.2 \pm 24.3[50-600]$ & 52.4 & 214.7 \\
BPN, (lpg) & $216.8 \pm 65.8[15-1800]$ & 100 & 476.1 \\
Muscle protozoa (Sarcocystis), (cps) & $2.4 \pm 0.9[1-10]$ & 32 & 4.5 \\
\hline
\end{tabular}

All samples taken for the parasitological study were collected during the first hour after death. Total solid rectal faeces and a portion $(3 \times 6 \mathrm{~cm})$ of diaphragm sinew were collected from each animal. Faeces were refrigerated and analysed within 24-48 h of collection; the muscle samples were stored in glycerine-ethanol ( $70 \%$ ethanol in glycerine) until analysis. Three grams of faeces were analysed by flotation (modified McMaster method; Central Veterinary Laboratory Weybridge 1973 ) with $50 \%$ zinc sulphate ( $\delta=$ 1.3). This polyvalent method allows the enumeration of lower density structures such as the eggs of gastrointestinal nematodes (Strongylida, Rhabditida, Trichuroidea), cestodes (Anoplocephalidae) and oocysts of intestinal coccidia (Eimeria spp.), as well as higher density structures such as the eggs of hepatic trematodes (Fasciola hepatica, Dicrocoelium dendriticum). Ten grams of faeces were analysed by the Baermann-Wetzel method (MAFF 1977) for the first-stage larvae of lung nematodes (Dictyocaulidae and Protostrongylidae). Microscopic identification and counting were performed using a McMaster chamber following the instructions of the MAFF (1977). Counts were expressed as eggs per gram (epg), oocysts per gram (opg) and larvae per gram (lpg) of faeces. Fourteen diaphragm sections, each the size of a grain of rice, were pressed between glass plates and observed under a compound microscope $(\times 40-100)$ for Sarcocystis spp. cysts, following the trichinoscopy technique in Directive 77/96 EEC (Annex I) for pork meat examination (EEC 1977). Counts were expressed as cysts animal per sample (cps). The prevalence, individual intensity and mean intensity of infestation were calculated for each parasite group (gastrointestinal nematodes, cestodes, trematodes, coccidian and lungworms) according to Margolis et al. (1982).

The sperm variable values showed a skewed distribution (Shapiro-Wilks $W$ test, $P<0.001$; Kolmogorov-Smirnov test and Lilliefors test for normality, $P<0.01)$ and were therefore arcsine-transformed before statistical analysis. The parasite counts also showed a skewed distribution and were arcsinh-transformed. The effects of age on counts for each parasite group and sperm quality were analysed by one-way analysis of variance (ANOVA). The $F$ test was used to examine differences in age between the animals from the different game reserves. Pearson correlation analysis was used to examine the correlations between reproductive variables and the counts for each parasite group. Principal components analysis (PCA) of the variancecovariance matrix of six sperm variables (percentage motile sperm, quality of motility, percentage viable sperm, percentage acrosome integrity, percentage positive endosmosis, percentage morphological abnormalities) was also performed. The Pearson correlation test was also used to examine the relationships between the factor loadings obtained by PCA and the parasite counts. Significance was set at $P<0.05$. All calculations were made using the STATISTICA v.5.0 software package (StatSoft 1995).

\section{Results}

Four parasite groups were detected by faecal analysis: gastrointestinal nematodes (order Strongylida), intestinal cestodes (order Anoplocephalidea), intestinal coccidia (order Eucoccidiidae) and bronchopulmonary nematodes (order Strongylida). Protozoa of the genus Sarcocystis (order Eucoccidiidae) were found by muscle biopsy. Bronchopulmonary nematodes were the most prevalent; protostrongylid nematode shedding was observed in all the studied animals. All four genera of the family Protostrongylidae (Muellerius, Neostrongylus, Cystocaulus and Protostrongylus) were iden-
Table 2 Sperm variable values (mean \pm S.E.) for fresh epididymal spermatozoa collected within $8 \mathrm{~h}$ of death

\begin{tabular}{lrr}
\hline & Epididymal spermatozoa & Range \\
\hline Percentage of motile sperm & $80.9 \pm 2.1$ & $45-90$ \\
Quality of motility (0-5) & $3.5 \pm 0.1$ & $2-4.5$ \\
Percentage of viable sperm & $80.4 \pm 2.3$ & $68-90$ \\
Percentage of acrosome integrity & $86.3 \pm 2.5$ & $45-98$ \\
Percentage of positive endosmosis & $83.6 \pm 1.0$ & $66-92$ \\
Percentage of morphological abnormalities & $8.8 \pm 1.6$ & $1-27$ \\
\hline
\end{tabular}


Table 3 Principal components analysis (PCA) of the variance-covariance matrix for six sperm variables: percentage of motile sperm, quality of motility, percentage of viable sperm, percentage of acrosome integrity, percentage of positive endosmosis, percentage of morphological abnormalities ( $n=43$ ibexes)

\begin{tabular}{lccc}
\hline Sperm variables & Factor loadings & $R^{2}$ & Significance \\
\hline Percentage of motile sperm & -0.89 & 0.79 & $P<0.001$ \\
Quality of motility (0-5) & -0.86 & 0.71 & $P<0.001$ \\
Percentage of viable sperm & -0.30 & 0.05 & $P=0.13$ \\
Percentage of acrosome integrity & -0.42 & 0.21 & $P<0.01$ \\
Percentage of positive endosmosis & -0.05 & 0.00 & $P=0.85$ \\
Percentage of morphological abnormalities & 0.69 & 0.51 & $P<0.001$ \\
Eigenvalue & 2.3 & & \\
Variance explained (\%) & 38.4 & & \\
\hline
\end{tabular}

tified. No larvae of the family Dictyocaulidae (genus Dictyocaulus) were detected. Two genera of intestinal cestodes of the family Anoplocephalidae were identified: Moniezia expansa and Moniezia benedeni. Intestinal coccidia detected in faecal analysis belonged to the genus Eimeria. Among the digestive tract parasites, gastrointestinal nematodes were the most common and cestodes the least (Table 1). Bronchopulmonary nematode larvae counts were $>350 \mathrm{lpg}$ in $21 \%$ of the animals, some of them (three animals, $7 \%$ ) reaching levels of $>10^{3} \mathrm{lpg}$. Muscle cysts of the genus Sarcocystis were present in $32 \%$ of the animals at intensities of 1-10 cysts per sample (Table 1). Most animals with high lpg or epg values were parasitised by both bronchopulmonary and gastrointestinal nematodes, as well as by Eimeria spp. (Table 1).

For the range of the animals studied (9-14 years), ANOVA revealed no influence of age $(P>0.05)$ on the prevalence or intensity of parasitism or reproductive variables. Age was, therefore, not included in following statistical tests. The $F$ test revealed no significant difference in age between the animals from the different game reserves $(F=2.32 ; P=0.18)$.

The sperm abnormalities encountered included narrow, small or big heads, detached normal heads, swollen or double midpieces and bent and coiled tails (Table 2). The diameter of the testicular parenchyma was $4.7 \pm 0.1 \mathrm{~cm}$ (mean \pm S.E; range $3.6-5.7 \mathrm{~cm}$ ).

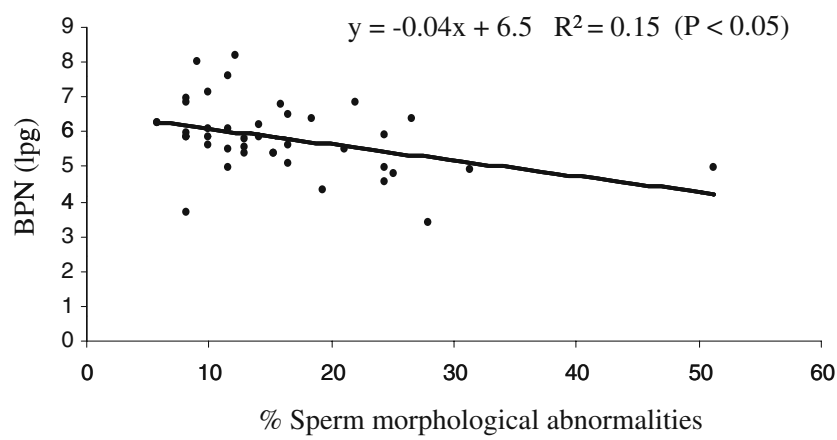

Fig. 1 Correlation between bronchopulmonary nematodes $(B P N)$ (arcsinh-transformed data) and the percentage of sperm morphological abnormalities (arcsine-transformed data)
PCA performed with the six sperm variables analysed revealed an axis explaining $38.4 \%$ of the variance with a corresponding Eigenvalue of 2.3. The percentage of motile sperm, the quality of motility and the percentage of morphological abnormalities showed high loadings indicating them to be strongly correlated $(P<0.001)$ with this axis (Table 3). No linear correlation was seen between the arcsinh-transformed parasite counts and the PCA factor loadings for sperm quality. When each sperm variable was analysed separately, a negative correlation $(R=-0.39 ; P=$ 0.01 ) was found between the shedding of larval lungworms (Protostrongylidae) and the percentage of sperm morphological abnormalities (Fig. 1). A trend towards a positive correlation $(R=0.27 ; P=0.08)$ was seen between the shedding of larval lungworms and testicle size (Fig. 2).

\section{Discussion}

The present findings regarding the parasitisation of Iberian ibexes by Sarcocystis spp. agree with the results of Granados et al. (2001) who, working in the same geographic region, showed moderate levels of prevalence compared to the high indices reported for Alpine ibex in Italy (Cornaglia et al. 1998). Larvae of the family Dictyocaulidae were not detected, unlike that reported for

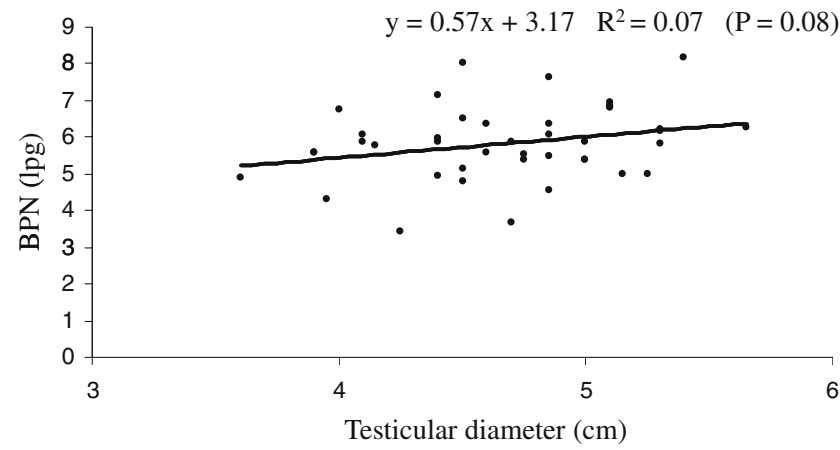

Fig. 2 Correlation between bronchopulmonary nematode larvae counts $(B P N)$ (arcsinh-transformed data) and testicle diameter (in centimeter) 
other populations of Iberian ibexes (Acevedo et al. 2005). The predominantly moderate excretion of other direct cycle parasites, such as gastrointestinal nematodes, might in part be due to environmental restraints, but may be also explained by the host population density being below tolerable limits. The adult age of the animals would also account for the moderate excretion levels observed; acquired immunity to strongylid gastrointestinal nematodes would have developed over a number of grazing seasons (Urquhart et al. 1987). The most remarkable parasitological findings of the present work were the high level of protostrongylid larva shedding observed in some animals compared to previous reports for this species (Acevedo et al. 2005), and the presence of Protostrongylidae in all the animals studied. These observations might be explained in part by the type of animals used in the present work, i.e., males selectively shot during the rutting season owing to their low quality.

Bronchopulmonary nematodes were the only parasite group showing a relationship with the reproductive variables studied. The shedding of larval lungworms was negatively correlated with the percentage of sperm morphological abnormalities, and showed a trend towards being positively correlated with testicle size. In this regard, recent studies have revealed that plasma testosterone concentrations are strongly associated with an increase in nematode load in natural populations of red deer (Malo et al. 2009). We have previously shown that reproductive effort is increased in dominant ibex males with larger horns, predisposing them to the shedding of lungworm larvae (Luzón et al. 2008). Similar observations have been made in naturally deceased wapiti (C. elaphus) males (Smith 1998). The latter author observed that animals clinically affected by psoroptic mange (Psoroptes spp.) had higher quality antlers than those apparently free of such parasitism. Horn size is also associated with sperm variable values; ibexes with higher quality horns show a lower number of sperm morphological abnormalities and higher sperm motility (Santiago-Moreno et al. 2007). The present findings, together with previous results obtained at our laboratory for this species (SantiagoMoreno et al. 2007; Luzón et al. 2008), show that, during the rutting season, bronchopulmonary larva output is associated with dominance, androgen secretion and quality sperm production. The high shedding rate of larval lungworms may be the response to a temporary increase in larva output due to a reactivation of arrested larval development (Luzón et al. 2008); this has been well documented for Cystocaulus ocreatus (Borchert 1981). Under natural conditions, a mass of inhibited larvae always remain ready to reassume development under certain circumstances such as the temporary weakening of the host immune status during the rutting season - a consequence of increased inter-male competition and courtship and mating activity (Zuk and Stoehr 2002).
Since the ibexes were selectively hunted for their relatively small horn development, the present sample cannot be considered random. However, the mean base perimeter and length measurements of the horns were close to those described in other studies in animals from the same game reserves (Santiago-Moreno et al 2007; Luzón et al. 2008). This suggests that horn length in these reserves is shorter than that seen in other ibex populations (Granados et al. 1997). The males used in the present study showed homogeneous horn development, and this secondary sexual characteristic could not, therefore, be used to distinguish dominance status.

Horn growth is regulated by testosterone which is also involved in semen production (Toledano-Díaz et al. 2007). Low levels of testosterone affect spermatogenesis and cause an increased number of sperm abnormalities (Malo et al. 2009; Santiago-Moreno et al. 2009). In contrast, high levels of testosterone stimulate spermatogenesis although a certain degree of immunosuppression may also be caused (Lehmann et al. 1988; Lehmann and Emmons 1989; Kelly 1995). Immunosuppression in these animals with better sperm quality and larger testicles may prevent autoimmune reactions against germ cells (Skau and Folstad 2005), but this could also justify the increase in the output of larva as a consequence of the reactivation of larvae whose development has been arrested.

In conclusion, the present findings appear to support the immunocompetence handicap hypothesis (Folstad and Karter 1992) and suggest there to be a cost associated with high testosterone levels (Malo et al. 2009). Specifically, and at least under the current study conditions and for the parasite groups detected, reproductive effort appears to be associated with depressed parasite resistance. It should be noted that the present work is a correlational study, and the question of whether reproductive variables are a cause or a consequence (or both) of parasite loads need to be experimentally tested.

Acknowledgements This work was funded by FEDER-INIA (grant FAU 2006-00001). The authors would like to thank the Sedella District Council (Ayuntamiento de Sedella, Málaga) for its help in setting up the local laboratory, the gamekeepers of the Regional Environmental Council of Málaga (D.P. Málaga, Consejería de Medio Ambiente, Junta de Andalucía), EGMASA (Empresa de Gestión Medioambiental, S.A.) for help in obtaining samples, and the Consejería de Medio Ambiente de Andalucia for its unfailing help in implementing the projects proposed.

\section{References}

Acevedo P, Cassinello J (2009) Biology, ecology and status of Iberian ibex Capra pyrenaica: a critical review and research prospectus. Mammal Rev 39:17-32 
Acevedo P, Vicente J, Alzaga V, Gortazar C (2005) Relationship between bronchopulmonary nematode larvae and relative abundances of Spanish ibex (Capra pyrenaica hispanica) from Castilla-La Mancha, Spain. J Helminthol 79:113-118

Al-Qarawi AA, Omar HM, Abdel-Rahman HA, El-Mougy SA, El-Belely M-S (2004) Trypanosomiasis-induced infertility in dromedary (Camelus dromedarius) bulls: changes in plasma steroids concentration and semen characteristics. Anim Reprod Sci 84:73-82

Alexander J, Stimson WH (1988) Sex hormones and the course of parasitic infection. Parasitol Today 4:189-193

Borchert A (1981) Parasitología veterinaria, 3rd edn. Acribia, Zaragoza [In Spanish]

Buckland ST, Anderson DR, Burnham KP, Laake JL, Borchers D, Thomas L (2001) Introduction to distance sampling: estimating abundance of biological populations. Oxford University Press, London, $\mathrm{p} 432$

Campbell RC, Dott HM, Glover TD (1956) Nigrosin eosin as a stain for differentiating live and dead spermatozoa. J Agric Sci 48:1-8

Central Veterinary Laboratory, Weybridge, Inglaterra (1973) Manual de técnicas de parasitología veterinaria. Ed. Acribia. Zaragoza, Spain, p 196 [In Spanish]

Cornaglia E, Giaccherino AR, Peracino V (1998) Ultrastructural morphology of sarcosporidiosis in alpine ibex (Capra ibex). Vet Parasitol 75:21-32

EEC (1977) Commission directive 77/96/EEC. Official Journal of the European Communities 26:69-104

Fandos P (1995) Factors affecting horn growth in male Spanish ibex (Capra pyrenaica). Mammalia 59:229-235

Folstad I, Karter AJ (1992) Parasites, bright males, and the immunocompetence handicap. Am Nat 139:603-622

Folstad I, Skarstein F (1997) Is male germ line control creating avenues for female choice? Behav Ecol 8:109-112

Granados E, Peréz JM, Soriguer RC, Fandos P, Ruiz-Martínez I (1997) On the biometry of the Spanish ibex, Capra pyrenaica, from Sierra Nevada (Southern Spain). Folia Zool 46:9-14

Granados JE, Pérez JE, Márquez FJ, Serrano E, Soriger RC, Fandos P (2001) La cabra montés (Capra pyrenaica, Schinz 1838). Galemys 13:3-37 [In Spanish]

Hamilton WD, Zuk M (1982) Heritable true fitness and bright birds: a role for parasites? Science 218:384-387

Hosken DJ, O'Shea JE (2001) Sperm production and immune function in two Australian bats, Chalinolobus morio and Nyctophilus geoffroyi. Ethol Ecol Evol 13:173-180

Isserhoff H, Sylvester PW, Held WZA (1986) Effects of Schistosoma mansoni on androgen regulated gene expression in the mouse. Mol Biochem Parasitol 18:401-412

Jeyendran R, Van Der Ven H, Perez-Pelaez M, Crabo B, Zaneveld L (1984) Development of an assay to assess the functional integrity of the human sperm membrane and its relation to other semen characteristics. J Reprod Fertil 70:219-228

Kelly RW (1995) Immunosuppressive mechanisms in semen: implications for contraceptions. Hum Reprod 10:1686

Lehmann D, Emmons LR (1989) Immunological phenomena observed in the testis and their possible role in infertility. Am J Reprod Immunol 19:43-52

Lehmann D, Siebold K, Emmons LR (1988) Androgens inhibit proliferation of human peripheral blood lymphocytes in vitro. Clin Immunol Immunopathol 46:122

Liljedal S, Folstad I, Skarstein F (1999) Secondary sex traits, parasites, immunity and ejaculate quality in the Arctic charr. Proc R Soc Lond B 266:1893-1898

Luzón M, Santiago-Moreno J, Meana A, Toledano-Díaz A, PulidoPastor A, Gómez-Brunet A, López-Sebastián A (2008) Parasitism and horn quality in male Spanish ibex (Capra pyrenaica hispanica) from Andalucía based on coprological analysis and muscle biopsy. Span J Agric Res 6:353-361
MAFF (1977) Manual of veterinary parasitological laboratory techniques. Technical Bulletin No. 18. Ministry of Agriculture, Fisheries and Food. Her Majesty's Stationary Office, London, p 131

Malo AF, Roldan E, Garde JJ, Soler AJ, Vicente J, Gortazar C, Gomendio M (2009) What does testosterone do for red deer males? Proc R Soc B 276:971-980

Margolis L, Esch GW, Holmes JC, Kuris AM, Schad GA (1982) The use of ecological terms in parasitology (Report of and $A d$ hoc Committee of the American Society of Parasitologists). J Parasitol 68:131-133

Masvaer M, Liljedal S, Folstad I (2004) Are secondary sex traits, parasites and immunity related to variation in primary sex traits in the Arctic char? Proc R Soc Lond B (Suppl) 271:S40-S42

Merila J, Andersson M (1999) Reproductive effort and success are related to haematozoan infections in blue tits. Ecoscience 6:421-428

Møller AP, Saino N (2004) Immune response and survival. Oikos 104:299-304

Morris RS, Meek AH (1980) Measurement and evaluation of the economic effects of parasitic disease. Vet Parasitol 6:165-184

Norris K, Anwar M, Read AF (1994) Reproductive effort influences the prevalence of haematozoan parasites in great tits. J Anim Ecol 63:601-610

Pelletier F, Page KA, Ostiguy T, Festa-Bianchet M (2005) Fecal counts of lungworm larvae and reproductive effort in bighorn sheep, Ovis canadensis. Oikos 110:473-480

Pursel V, Johnson L (1974) Glutaraldehyde fixation of boar spermatozoa for acrosome evaluation. Theriogenology 1:63-68

Rhodes AP (1975) Seminal degeneration associated with chorioptic mange of the scrotum of rams. Aust Vet J 51:428-432

Santiago-Moreno J, González-Bulnes A, Gómez-Brunet A, LópezSebastián A (2000) Effect of birth date on body weight, scrotal circumference and horn dimension growth in captive juvenile mouflon (Ovis gmelini musimon) rams. Game Wildl Sci 17:179_ 187

Santiago-Moreno J, Toledano-Díaz A, Pulido-Pastor A, GómezBrunet A, González-Bulnes A, López-Sebastián A (2004) Postthawing evaluation of Spanish ibex (Capra pyrenaica hispanica) epididymal spermatozoa recovered postmortem. Span J Agric Res 2:337-340

Santiago-Moreno J, Gómez-Brunet A, Toledano-Díaz A, GonzálezBulnes A, Picazo RA, López-Sebastián A (2005) Influence of age on the relationship between annual changes in horn growth rate and prolactin secretion in the European Mouflon (Ovis gmelini musimon). Anim Reprod Sci 85:251-261

Santiago-Moreno J, Toledano-Díaz A, Pulido-Pastor A, Gómez-Brunet A, López-Sebastián A (2007) Horn quality and postmortem sperm parameters in Spanish ibex (Capra pyrenaica hispanica). Anim Reprod Sci 99:354-362

Santiago-Moreno J, Coloma MA, Dorado J, Pulido-Pastor A, GómezGuillamon F, Salas-Vega R, Gómez-Brunet A, López-Sebastián A (2009) Cryopreservation of Spanish ibex (Capra pyrenaica) sperm obtained by electroejaculation outside the rutting season. Theriogenology 71:1253-1260

Sekoni VO (1992) Effect of Trypanosoma vivax infection on semen characteristics of Yankasa rams. Brit Vet J 148:501-506

Sekoni VO, Rekwot PI, Bawa EK (2004) Effects of Trypanosoma vivax and Trypanosoma congolense infections on the reaction time and semen characteristics of Zebu (Bunaji) $\times$ Friesian crossbred bulls. Theriogenology 61:55-62

Skarstein F, Folstad I, Liljedal S (2001) Whether to reproduce or not: immune suppression and cost of parasites during reproduction in the Arctic charr. Can J Zool 79:271-278

Skau PA, Folstad I (2005) Does immunity regulate ejaculate quality and fertility in humans? Behav Ecol 16:410-416

Smith BL (1998) Antler size and winter mortality of elk: effects of environment, birth year, and parasites. J Mammal 79:1038-1044 
Sorci G, Clobert J, Michalakis Y (1996) Cost of reproduction and cost of parasitism in the common lizard, Lacerta vivipara. Oikos $76: 121-130$

StatSoft (1995) STATISTICA ${ }^{\circledR}$ for windows. Version 5.0 [computer program]. StatSoft Inc, Tulsa

Toledano-Díaz A, Santiago-Moreno J, Gómez-Brunet A, PulidoPastor A, López-Sebastián A (2007) Horn growth related to testosterone secretion in two wild Mediterranean ruminant species Spanish ibex (Capra pyrenaica hispanica) and mouflon (Ovis orientalis musimon). Anim Reprod Sci 102:300-307

Tumkiratiwong P, Sukkachart H, Buapuan T, Tungtrongchitr R, Tungtrongchitr A (2006) Riboflavin-deficient and Trichinella spiralis-induced stresses on plasma corticosterone associated with spermatogenesis in male Wistar rats. Southeast Asian J Trop Med Public Health 37:250-256

Urquhart GM, Armour J, Duncan JL, Dunn AM, Jennings FW (1987) Veterinary Parasitology. University Press, Cambridge, p 286

Vicente J, Pérez-Rodríguez L, Gortazar C (2007) Sex, age, size and kidney fat of red deer relative to infection intensities of the lungworm Elaphostrongylus cervi. Naturwissenschaften 94:581-587

Zuk M (1990) Reproductive strategies and disease susceptibility: an evolutionary viewpoint. Parasitol Today 6:231-233

Zuk M, Stoehr AM (2002) Immune defense and host life history. Am Nat 160(Suppl 4):S9-S22 